\title{
Poly(borosiloxanes) as Precursors for Carbon Fiber Ceramic Matrix Composites
}

\author{
Renato Luiz, Siqueira, Inez Valéria Pagotto Yoshidab, \\ Luiz Claudio Pardinic, Marco Antônio Schiavon ${ }^{\text {a* }}$ \\ ${ }^{a}$ Departamento de Ciências Naturais, Universidade Federal de São João Del Rei - UFSJ, \\ Campus Dom Bosco, 36301-160 São João Del Rei - MG, Brazil \\ ${ }^{\mathrm{b}}$ Instituto de Química, Universidade Estadual de Campinas - UNICAMP, \\ CP 6154, 13083-970 Campinas - SP, Brazil \\ 'Divisão de Materiais, CTA, Instituto de Aeronáutica e Espaço, \\ 12228-904 São José dos Campos - SP, Brazil
}

Received: December 14, 2006; Revised: March 6, 2007

\begin{abstract}
Ceramic matrix composites (CMCs), constituted of a silicon boron oxycarbide ( $\mathrm{SiBCO}$ ) matrix and unidirectional carbon fiber rods as a reinforcement phase, were prepared by pyrolysis of carbon fiber rods wrapped in polysiloxane (PS) or poly(borosiloxane) (PBS) matrices. The preparation of the polymeric precursors involved hydrolysis/condensation reactions of alkoxysilanes in the presence and absence of boric acid, with $\mathrm{B} / \mathrm{Si}$ atomic ratios of 0.2 and 0.5 . Infrared spectra of PBS showed evidence of Si-O-B bonds at $880 \mathrm{~cm}^{-1}$, due to the incorporation of the crosslinker trigonal units of $\mathrm{BO}_{3}$ in the polymeric network. $\mathrm{X}$ ray diffraction analyses exhibited an amorphous character of the resulting polymer-derived ceramics obtained by pyrolysis up to $1000{ }^{\circ} \mathrm{C}$ under inert atmosphere. The $\mathrm{C} / \mathrm{SiBCO}$ composites showed better thermal stability than the $\mathrm{C} / \mathrm{SiOC}$ materials. In addition, good adhesion between the carbon fiber and the ceramic phase was observed by SEM microscopy.
\end{abstract}

Keywords: precursors, poly(borosiloxanes), carbon fibers, composites

\section{Introduction}

Polymer-derived ceramics are presently being studied for application as protective coatings ${ }^{1}$, fibers ${ }^{2}$ and ceramic matrix composites ${ }^{3}$ because they have outstanding high temperature properties. The preparation of ceramic matrix composites (CMCs) from polymeric precursors has been a particularly promising area of research due to the possibility of obtaining new ceramic materials whose properties can be tailored to specific needs for long life service and load bearing applications ${ }^{4}$.

Silicon oxycarbide $(\mathrm{SiOC})$ and silicon carbonitride $(\mathrm{SiCN}) \mathrm{de}-$ rived glasses have attracted attention for their peculiar high temperature properties, such as low creep rates ${ }^{5}$ and high thermal stability ${ }^{6}$. They are easily produced by thermal degradation of polysiloxane and polysilazanes, respectively, which leads to a random network of covalent $\mathrm{Si}-\mathrm{C}, \mathrm{Si}-\mathrm{N}$ and $\mathrm{Si}-\mathrm{O}$ bonds. These materials have excellent stability against crystallization. Amorphous $\mathrm{SiCN}$ only leads to $\beta-\mathrm{SiC}_{\mathrm{Si}} \mathrm{N}_{4}$ nanocomposite above $1450{ }^{\circ} \mathrm{C}^{7}$, while $\mathrm{SiCO}$ starts to separate into amorphous silica and nanocrystalline $\beta$-SiC $(1 \mathrm{~nm})$ with a low crystallite growth rate at the lower temperature of $1300^{\circ} \mathrm{C}$. At $1500{ }^{\circ} \mathrm{C}, \beta-\mathrm{SiC}$ crystallites reach a maximum size of $2-3 \mathrm{~nm}^{8}$.

The incorporation of heteroatoms such as boron in these materials can be performed because the molecular structures of the polymeric precursors can be easily tailored ${ }^{9}$. This approach is a recent strategy for structural and compositional ceramic changes that improve the properties of the final materials, making new highly demanding applications possible, such as re-radiative thermal protection systems. In the $\mathrm{SiCN}$ system, the addition of B leads to the production of SiBCN glasses which may display the highest thermal stability ever shown for an amorphous phase under inert atmosphere, with a crystallization temperature above $1700^{\circ} \mathrm{C}$ and decomposition temperatures even up to $2200{ }^{\circ} \mathrm{C}^{10}$. The mechanism of the role of boron in increasing the stability of the disordered SiCN network against devitrification is not yet completely understood. However, it has been proposed that $\mathrm{B}$ can form turbostratic BN layers which can act as a barrier for the diffusing atoms, but can also increase the network disorder of $\mathrm{SiCN}$, making the structural reorganization toward crystalline phases more difficult ${ }^{10}$.

Boron is also known to protect carbonaceous materials by carbon active site poisoning or by forming a boron oxide film on the surface of the material ${ }^{11}$. In this field, the general consensus has been that substitutional boron acts as an inhibitor of carbon oxidation, redistributing the $\pi$ electrons, which inhibits the $\mathrm{CO}$ and $\mathrm{CO}_{2}$ desorption and enhances the graphitization of carbon.

Despite many relevant studies regarding the role of substitutional boron in carbon oxidation protection ${ }^{12}$, controversy still remains, and many more experimental results must be discussed. Indeed, different approaches have been used to produce B-doped carbon materials ${ }^{11-13}$. Although each study used different materials and experimental conditions, the final goal for each was the improvement of the carbon oxidation stability with the introduction of B in the system.

Taking into account the above ideas, this work reports the synthesis and thermal characterization of polysiloxanes (PS) and poly(borosiloxanes) (PBS), aiming to use these polymers as precursors of ceramic matrices for the protection of carbon fibers in ceramic matrix composites (CMCs). $\mathrm{C} / \mathrm{SiOC}$ and $\mathrm{C} / \mathrm{SiBOC}$ composites were prepared by impregnation of the liquid precursors in unidirectional carbon fiber tows followed by curing, drying and pyrolysis. Results will be presented regarding the preparation and polymer-to-ceramic conversion, as well as the properties of the resulting CMCs involving carbon fibers. 


\section{Experimental}

\subsection{Preparation of the polymeric precursors}

Poly(borosiloxane) (PBS) gels were synthesized by starting with methyltriethoxysilane, $\mathrm{CH}_{3} \mathrm{Si}\left(\mathrm{OCH}_{2} \mathrm{CH}_{3}\right)_{3}$ MTES (Aldrich), adding an appropriate amount of boric acid, $\mathrm{B}(\mathrm{OH})_{3}$ (Vetec Brasil), and stirring until complete dissolution was achieved ${ }^{14,15}$. Compositions with nominal $\mathrm{B} / \mathrm{Si}$ atomic ratios of 0.2 and 0.5 were prepared. The clear solutions were then cast in plastic tubes and left open for gelation. Wet gels were dried for at least 10 days at $60{ }^{\circ} \mathrm{C}$. For comparison purposes, gels without $\mathrm{B}$ (polysiloxane, PS) were prepared from methyltriethoxysilane. In a typical preparation, MTES was hydrolyzed using a $\mathrm{H}_{2} \mathrm{O} /\left(\mathrm{OCH}_{2} \mathrm{CH}_{3}\right)$ ratio of 1 at $70{ }^{\circ} \mathrm{C}$ for 15 minutes under acidic conditions $(\mathrm{HCl}, \mathrm{pH}=1)$. Afterward, the solution was cooled to room temperature, and the sol was gelled and dried at $70{ }^{\circ} \mathrm{C}$ for at least 10 days.

\subsection{Glass preparation}

Gel fragments of PS and PBS were converted into the SiOC and $\mathrm{SiBOC}$ glasses, respectively, through pyrolysis in flowing $\mathrm{Ar}$ $(100 \mathrm{~mL} / \mathrm{min})$ at $1000{ }^{\circ} \mathrm{C}$. The pyrolysis was carried out in a furnace (EDG10P-S) by placing the sample in an alumina crucible, and then in an alumina tube using a heating rate of $10{ }^{\circ} \mathrm{C} / \mathrm{min}$ with a holding time of 1 hour at the maximum temperature. For the polymer-to-ceramic conversion studies, the gel samples were heated with the same heating schedule at 300 and $700{ }^{\circ} \mathrm{C}$. Ceramic yield was determined by thermogravimetric analysis.

\subsection{Ceramic matrix composite preparation}

$\mathrm{C} / \mathrm{SiCO}$ and $\mathrm{C} / \mathrm{SiBCO}$ composites were prepared by impregnation of ex-PAN carbon fiber tows with the corresponding sol precursor. The carbon fibers were manufactured by Hexcel Co. The fiber tows were left immersed in the sol for a period of 24 hours. The polymeric-impregnated fiber tows were then passed through cylindrical polyethylene tubes (10 $\mathrm{mm}$ length and $3 \mathrm{~mm}$ internal diameter), and kept inside the tubes for seven days to complete the cure of the polymeric precursor. After that, green bodies were further dried at $60{ }^{\circ} \mathrm{C}$ for seven days. Finally, they were pyrolysed under an inert $\mathrm{Ar}$ atmosphere using the previously described heat schedule.

\subsection{Characterization techniques}

Thermogravimetric analysis (TGA) of the gels and green bodies were performed on a thermoanalyzer (TA Instruments 2950) equipped with an alumina tube furnace and alumina crucibles. Typically, tests were performed in flowing argon or synthetic air, with a heating rate of $10^{\circ} \mathrm{C} / \mathrm{min}$ up to $1000^{\circ} \mathrm{C}$. Fourier transform infrared spectra (FTIR) were recorded using Bomem MB series equipment. FTIR spectra were obtained on $\mathrm{KBr}$ pellets in the transmission mode, recording 32 scans with a resolution of $4 \mathrm{~cm}^{-1}$. XRD spectra were recorded on a diffractometer (Shimadzu, model XD3A) using $\mathrm{Cu} \mathrm{K} \alpha$ radiation $(\lambda=0.15418 \mathrm{~nm})$. Microstructural characterization was performed by scanning electron microscopy (SEM) using an electronic microscope (LEO 435VPI) operating with an accelerating voltage of $20 \mathrm{kV}$, and by optical microscopy (OM) using an Olympus BH microscope with 250x magnification.

\section{Results and Discussion}

\subsection{Synthesis and characterization of the polymeric precursors}

The reactions involved in the synthesis of the polymeric precursor networks PS and PBS can be represented by the Equations 1, 2 and 3, where $\mathrm{R}^{\prime}$ is the ethyl group $\left(-\mathrm{CH}_{2} \mathrm{CH}_{3}\right)$ :

$$
\begin{aligned}
& =\mathrm{B}-\mathrm{OH}+=\mathrm{Si}-\mathrm{OR}^{\prime} \longrightarrow=\mathrm{B}-\mathrm{OR}^{\prime}+=\mathrm{Si}-\mathrm{OH} \\
& =\mathrm{B}-\mathrm{OH}+=\mathrm{Si}-\mathrm{OH} \longrightarrow=\mathrm{B}-\mathrm{O}-\mathrm{Si}=+\mathrm{H}_{2} \mathrm{O} \\
& =\mathrm{B}-\mathrm{OH}+=\mathrm{S}-\mathrm{OR}^{\prime} \longrightarrow=\mathrm{B}-\mathrm{O}-\mathrm{Si}=+\mathrm{R}^{\prime} \mathrm{OH}
\end{aligned}
$$

$\mathrm{B}(\mathrm{OH})_{3}$ has a low solubility in the alkoxysilane system. However, it has been shown that reaction (1) occurs first and is followed by reactions (2) and (3) ${ }^{16}$. As B-OEt is formed by reaction (1), the solubility of the $\mathrm{B}(\mathrm{OH})_{3-\mathrm{x}}(\mathrm{OEt})_{\mathrm{x}}(1<\mathrm{x}<3)$ species increases over the course of the reaction. In addition, the alcohol formed in step (3) also helps the dissolution of boric acid ${ }^{17}$. The gelation times for the hydrolysis of methytrietoxisilane $\left(\mathrm{CH}_{3} \mathrm{Si}(\mathrm{OEt})_{3}\right)$ with boric acid at the $\mathrm{B} / \mathrm{Si}$ atomic ratios of 0.2 and 0.5 were roughly 13 and 10 days, respectively. These times suggest that the boric acid takes part in the slowest step of the gel network formation. All hybrid gels were monolithic and transparent.

FTIR spectra of the hybrid gels derived from MTES are shown in Figure 1. The symbols $\delta, v$ and $\rho$ mean, respectively, the vibration modes of angular deformation, stretching and "rocking". The freeboron (PS) gel spectrum displayed two broad and intense absorption peaks in the range of $\sim 1200$ to $1000 \mathrm{~cm}^{-1}$, which are related to $\mathrm{Si}-\mathrm{O}-\mathrm{Si}$ bonds. Other bands related to the $\mathrm{Si}-\mathrm{CH}_{3}$ group appeared at $1275 \mathrm{~cm}^{-1}\left(\delta \mathrm{C}-\mathrm{H}, \mathrm{Si}-\mathrm{CH}_{3}\right)$ and $770 \mathrm{~cm}^{-1}\left(\rho \mathrm{C}-\mathrm{H}, \mathrm{SiCH}_{3}\right)$, in addition to the $v \mathrm{C}-\mathrm{H}$ band at $2975 \mathrm{~cm}^{-1}$ (not shown) and $v \mathrm{Si}-\mathrm{C}$ at $\sim 800 \mathrm{~cm}^{-1}$. For the gels obtained in the systems containing boron, the broad absorption peaks between 1300 and $1500 \mathrm{~cm}^{-1}$ were assigned to $\mathrm{vB}-\mathrm{O}$, and that at $1195 \mathrm{~cm}^{-1}$ was associated with $\delta \mathrm{B}-\mathrm{OH}$. The band at $540 \mathrm{~cm}^{-1}$ corresponding to $\delta \mathrm{O}-\mathrm{B}-\mathrm{O}$ was also observed. The most significant band in the gels was the one observed at $\sim 880 \mathrm{~cm}^{-1}$ due to the Si-O-B bonds ${ }^{17}$, which was observed in all gel compositions with boron.

The polymer-to-ceramic conversion was followed up by FTIR (spectra not shown). In these spectra, the decrease of the relative intensities of the organic group absorptions and the broadening of the $\mathrm{Si}-\mathrm{O}-\mathrm{Si}$ absorptions were observed with the increase of the pyrolysis temperature. The disappearance of the band assigned to the $\mathrm{Si}-\mathrm{O}-\mathrm{B}$ bond was due to the simultaneous broadening of the $\mathrm{Si}-\mathrm{O}$ and $\mathrm{Si}-\mathrm{C}$ bands. These structural rearrangements in the materials led to the formation of silicon oxycarbide glasses $\left(\mathrm{SiO}_{\mathrm{x}} \mathrm{C}_{4-\mathrm{x}}\right)$ and boron oxycarbide glasses $\left(\mathrm{BO}_{\mathrm{x}} \mathrm{C}_{3-\mathrm{x}}\right)$ homogeneously dispersed in these ceramics ${ }^{18,19}$.

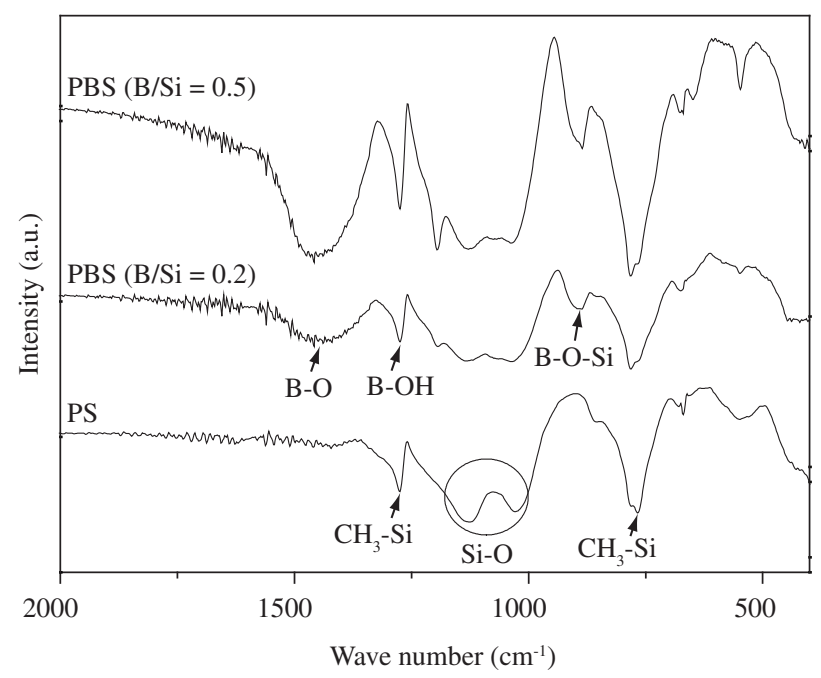

Figure 1. FTIR spectra of PS and PBS gels derived from MTES. 
Figure 2 shows TGA curves recorded for the PS and PBS gels derived from MTES during pyrolysis in flowing argon. The boron-free gels displayed the same thermogravimetric profiles, and three main degradation steps were observed for these samples. The first, in the range of $\sim 120$ to $250{ }^{\circ} \mathrm{C}$, was probably associated to the evolution of water and free oligomers trapped in gels, in addition to the evolution of water from the boric acid or from condensation reactions (2), in the case of PBS samples. The second step in the temperature range of $\sim 260$ to $500{ }^{\circ} \mathrm{C}$ was associated with the cleavage of $\mathrm{Si}-\mathrm{O}$ and $\mathrm{Si}-\mathrm{C}$ bonds, and the third step, in the temperature range of $\sim 500$ to $800{ }^{\circ} \mathrm{C}$, was related to the polymer-to-ceramic conversion of the material, with the formation of silicon oxycarbide glasses $(\mathrm{SiOC})^{17}$. For the PBS gels, TGA curves displayed similar behaviour, with significant weight losses in the range of 110 to $150{ }^{\circ} \mathrm{C}$ due to boron evolution. The intensity of this loss was proportional to the boron content. The ceramic yields of the boron-free gels and those with a B/Si ratio of 0.2 were higher than that observed for the sample with a B/Si ratio of 0.5 , due to the more intense boron losses at low temperatures.

Typical XRD patterns of amorphous materials were observed for PS- and PBS-derived glasses obtained at $1000^{\circ} \mathrm{C}$ from MTES gels, as shown in Figure 3. In addition, a broad halo with a maximum centered at $\sim 23^{\circ}(2 \theta)$ was observed, which was associated with silica domains at the beginning of the organization stage. For the sample derived from the gels with a $\mathrm{B} / \mathrm{Si}$ ratio of 0.5 , besides this halo, peaks at $14.7^{\circ}$ and $28.2^{\circ}(2 \theta)$ were assigned to the boron oxide crystalline phase. As the $\mathrm{B} / \mathrm{Si}$ ratio increased from 0.2 to 0.5 , the formation of the boron oxide crystalline phase became favored, suggesting the formation of $\mathrm{BO}_{3}$-clusters in the gels with an atomic ratio of $\mathrm{B} / \mathrm{Si}=0.5$.

\subsection{Characterization of ceramic matrix composites}

Figure 4 shows TGA curves recorded under oxidant atmosphere of the carbon fiber, and of the CMCs, derived from PS and PBS with atomic ratios of $\mathrm{B} / \mathrm{Si}=0.2$ and 0.5 , obtained at $1000{ }^{\circ} \mathrm{C}$ and prepared with MTES. For carbon fibers only, one degradation process was observed between 400 and $700{ }^{\circ} \mathrm{C}$, due to the evolution of volatile products such as $\mathrm{CO}$. The activation energy of this degradation process was $112.8 \pm 0.8 \mathrm{~kJ} \cdot \mathrm{mol}^{-1}$ as determined by the dynamic thermogravimetric method ${ }^{20}$, which agrees with most values reported in the literature for similar fibers ${ }^{21}$.

By examining the thermogravimetric profiles of $\mathrm{C} / \mathrm{SiOC}$ and $\mathrm{C} /$ $\mathrm{SiBOC}$ prepared with an atomic ratio of $\mathrm{B} / \mathrm{Si}=0.2$, both composites showed a better stability then the carbon fiber. For the composite

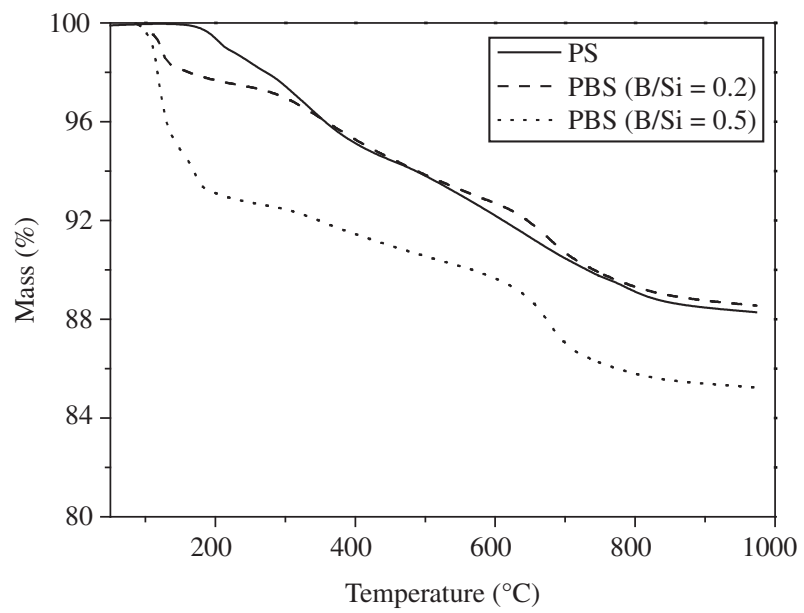

Figure 2. TGA curves for PS and PBS gels derived from MTES (air, $\left.10^{\circ} \mathrm{C} / \mathrm{min}\right)$. obtained from PBS with an atomic ratio of $\mathrm{B} / \mathrm{Si}=0.2$, a slight gain in stability was observed in relation to the $\mathrm{CMC}$ obtained from the parent boron-free polysiloxane (PS). However, the C/SiBOC composite prepared with the atomic ratio of $\mathrm{B} / \mathrm{Si}=0.5$ showed much better thermal stability. This increase of stability is therefore related to the boron content in the material.

The resulting composites obtained at $1000{ }^{\circ} \mathrm{C}, \mathrm{C} / \mathrm{SiCO}$ and $\mathrm{C} /$ $\mathrm{SiBCO}$, were stable monolithics. This characteristic was observed for all composites obtained from the PBS and PS precursors, including the green bodies. Figure 5 illustrates a representative SEM micrograph of the green body prepared from PBS-derived MTES with an atomic ratio of $\mathrm{B} / \mathrm{Si}=0.2$. It can be observed that the carbon fibers were homogeneously distributed in the polymeric precursor with good adhesion.

Figure 6 presents SEM and optical micrographs for a CMC obtained from MTES-derived PBS (with $\mathrm{B} / \mathrm{Si}=0.2$ ). Ceramic matrices displayed good adhesion to the carbon fibers, especially for CMCs obtained from precursors containing boron $(\mathrm{B} / \mathrm{Si}=0.2)$, as can be seen in Figure 6. However, the micrograph of the pyrolysed composite also

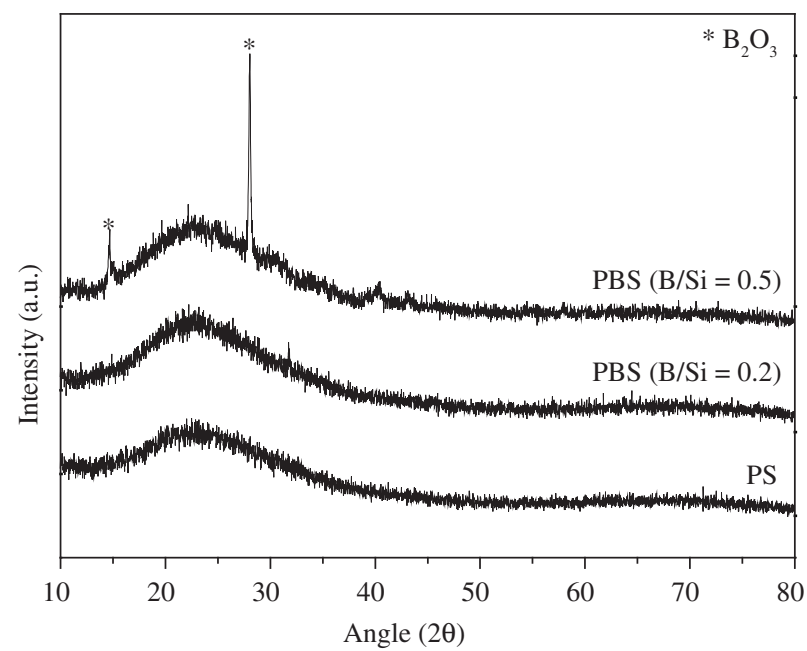

Figure 3. $\mathrm{X}$ ray diffraction patterns of PS- and PBS-derived MTES glasses obtained at $1000^{\circ} \mathrm{C}$.

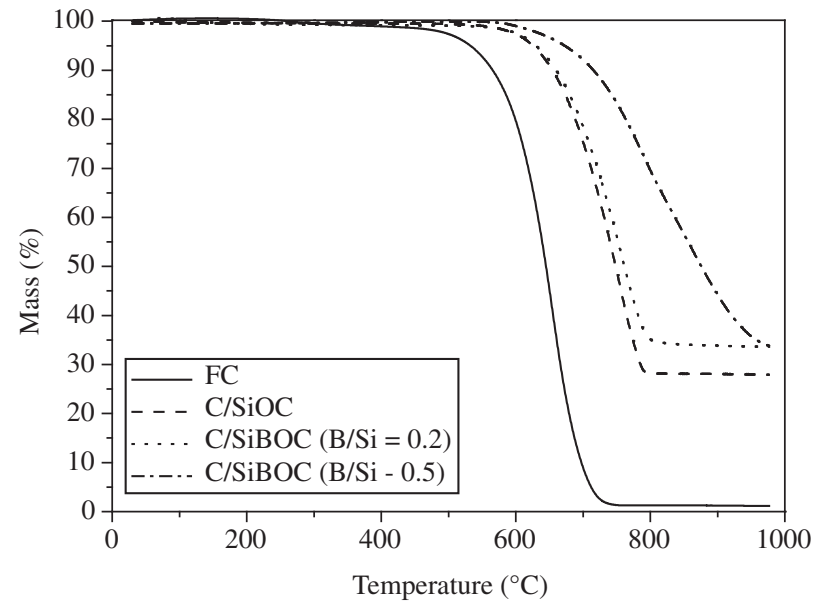

Figure 4. TGA curves of the carbon fiber and the $\mathrm{CMCs}$ obtained at $1000^{\circ} \mathrm{C}$ for the PS and PBS derived-MTES (air, $10{ }^{\circ} \mathrm{C} / \mathrm{min}$ ). 


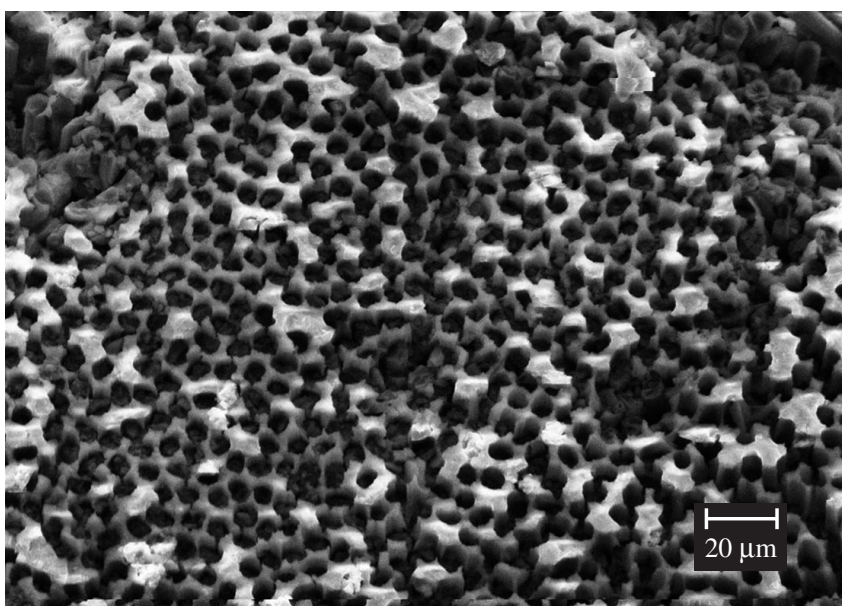

Figure 5. SEM micrograph of the green body prepared from PBS-derived MTES with an atomic ratio of $\mathrm{B} / \mathrm{Si}=0.2$.

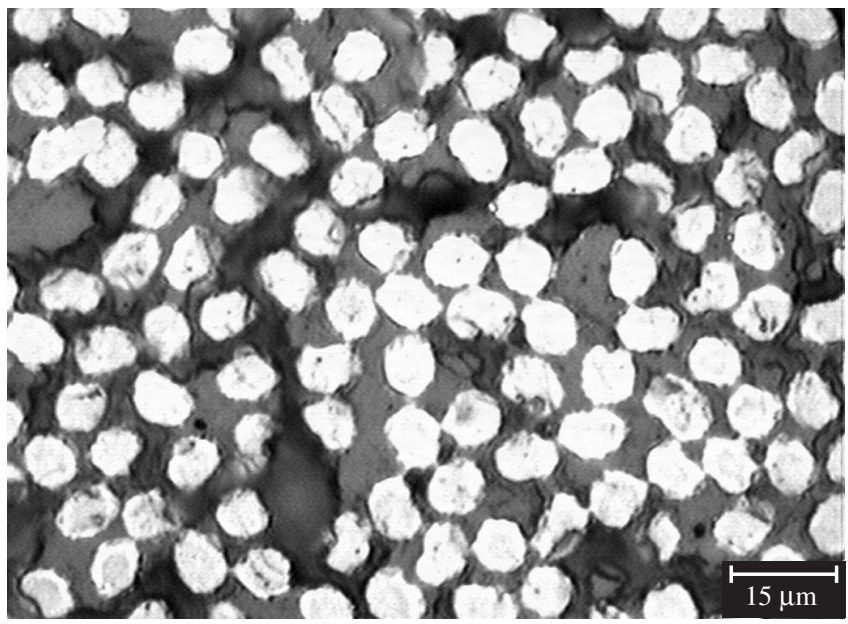

(a)

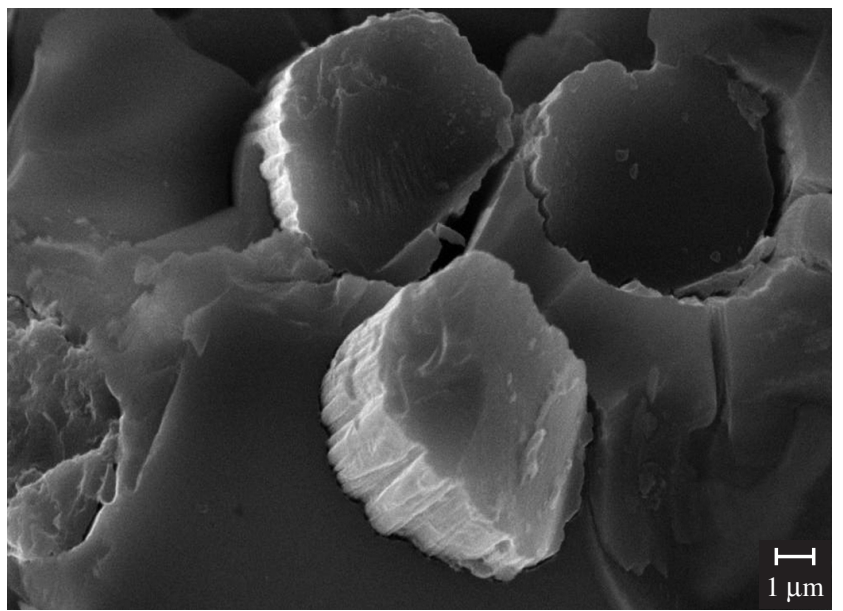

(b)

Figure 6. a) Optical; and b) SEM micrographs of the CMC obtained from MTES-derived PBS $(\mathrm{B} / \mathrm{Si}=0.2)$.

shows pores and micro-cracks. These micro-cracks could be related to the method of sample preparation for SEM analysis as well as to the weight loss during the pyrolysis process. The micrograph shown in Figure $6 b$ better supports the former idea.

\section{Conclusions}

This study demonstrates that poly(borosiloxane) networks are excellent precursors of ceramic materials in the SiBOC system. Gels bearing homogeneous $\mathrm{Si}-\mathrm{O}-\mathrm{B}$ bonds can be easily prepared using boric acid as the precursor of trigonal $\mathrm{BO}_{3}$ units in the siloxane network. The ceramic obtained at $1000{ }^{\circ} \mathrm{C}$ from poly(borosiloxanes) can be considered to be silicon-boron oxycarbide glass. It was also observed that poly(borosiloxanes) prepared with a $\mathrm{B} / \mathrm{Si}$ ratio of 0.5 displayed phase segregation of the boron oxide phase after pyrolysis at $1000{ }^{\circ} \mathrm{C}$, probably due to the formation of $\mathrm{BO}_{3}$-cluster units in the precursor. The polymeric precursors were adequate in wrapping carbon fibers, giving rise to stable green bodies and CMCs. The resulting materials exhibited better thermal stability than the carbon fiber, especially the PBS-derived MTES prepared with a B/Si ratio of 0.5 . This study showed that poly(borosiloxanes) are promising materials for the oxidation protection of carbon fibers, and consequently for thermal protection systems.

\section{Acknowledgments}

We gratefully acknowledge financial support from FAPEMIG (Grant CEX-925/04) and CNPq (Grant 478563/2004-3).

\section{References}

1. Ducarroir M, Zhang W, Berjoan R. SiCN coatings prepared by PACVD from TMS-NH $\mathrm{N}_{3}$ air system on steel. J. Physique IV. 1993; 3(C3):247-254.

2. Lipowitz J. Polymer-derived ceramic fibers. Ceramic Bulletin. 1991; 70:1888-1898.

3. Schiavon MA, Yoshida IVP. Ceramic matrix composites derived from $\mathrm{CrSi}_{2}$-filled polysiloxane. Journal of Materials Science. 2004; 39(14):4507-4514.

4. Odeshi AG, Mucha H, Wielage B. Manufacture and characterisation of a low cost carbon fibre reinforced $\mathrm{C} / \mathrm{SiC}$ dual matrix composite. Carbon. 2006; 44(10):1994-2001.

5. Riedel R, Ruswisch LM, An L, Raj R. Amorphous Silicoboron Carbonitride Ceramic with Very High Viscosity at Temperatures above $1500^{\circ} \mathrm{C}$. Journal of the American Ceramic Society. 1998; 81(12):3341-3345.

6. Ishikawa T, Kohtoku Y, Kumagawa K, Yamamura T, Nagasawa T. Highstrength alkali-resistant sintered $\mathrm{SiC}$ fibre stable to 2,200 degrees C. Nature. 1998; 391:773-775.

7. Schiavon MA, Sorarù GD, Yoshida IVP. Synthesis of a polysilazane network and its evolution to silicon carbonitride glass. Journal of NonCrystalline Solids. 2002; 304(1-3):76-83.

8. Turquat $\mathrm{C}$, Kleebe HJ, Gregori G, Walter S, Sorarù GD. Transmission Electron Microscopy and Electron Energy-Loss Spectroscopy Study of Nonstoichiometric Silicon-Carbon-Oxygen Glasses. Journal of the American Ceramic Society. 2001; 84(10):2189-2196.

9. Riedel R, Mera G, Hauser R, Klonczynski A. Silicon-Based PolymerDerived Ceramics: Synthesis Properties and Applications - A Review. Journal of the Ceramic Society of Japan. 2006; 114(6):425-444.

10. Wang Z-C, Aldinger F, Riedel R. Novel Silicon-Boron-Carbon-Nitrogen Materials Thermally Stable up to $2200{ }^{\circ} \mathrm{C}$. Journal of the American Ceramic Society. 2001; 84(10):2179-2183.

11. Labruquère $S$, Blanchard $H$, Pailler R, Naslain R. Enhancement of the oxidation resistance of interfacial area in $\mathrm{C} / \mathrm{C}$ composites. Part I: oxidation resistance of $\mathrm{B}-\mathrm{C}, \mathrm{Si}-\mathrm{B}-\mathrm{C}$ and $\mathrm{Si}-\mathrm{C}$ coated carbon fibres. Journal of the European Ceramic Society. 2002; 22(7):1001-1009.

12. Lee Y-J, Joo H-J, Radovic LR. Preferential distribution and oxidation inhibiting / catalytic effects of boron in carbon fiber reinforced carbon (CFRC) composites. Carbon. 2003; 41(13):2591-2600.

13. Ehrburger P, Baranne P, Lahaye J. Inhibition of the Oxidation of CarbonCarbon Composite by Boron Oxide. Carbon. 1986; 24(4):495-499. 
14. Sorarù GD, Babonneau F, Gervais $\mathrm{C}$, Dallabona N. Hybrid $\mathrm{RSiO}_{15} / \mathrm{B}_{2} \mathrm{O}_{3}$ Gels from Modified Silicon Alkoxydes and Acid Boric. Journal of Sol-Gel Science and Technology. 2000; 18(1):11-19.

15. Schiavon MA, Gervais $\mathrm{C}$, Babonneau F, Sorarù GD. Crystallization Behavior of Novel Silicon Boron Oxycarbide Glasses. Journal of the American Ceramic Society. 2004; 82(2):203-208.

16. Irwin AD, Holmgren JS, Zerda TW, Jonas J. Spectroscopic investigations of borosiloxane bond formation in the sol-gel process. Journal of NonCrystalline Solids. 1987; 89(1-2):191-205.

17. Sorarù GD, Dallabona N, Gervais C, Babonneau F. Organically Modified $\mathrm{SiO}_{2}-\mathrm{B}_{2} \mathrm{O}_{3}$ Gels Displaying a High Content of Borosiloxane (=B-O-Si=) Bonds. Chemistry of Materials. 1999; 11(4):910-919.
18. Gervais C, Babonneau F, Dallabonna N, Sorarù GD. Sol-Gel-Derived Silicon-Boron Oxycarbide Glasses Containing Mixed Silicon Oxycarbide $\left(\mathrm{SiC}_{\mathrm{x}} \mathrm{O}_{4-\mathrm{x}}\right)$ and Boron Oxycarbide $\left(\mathrm{BC}_{\mathrm{y}} \mathrm{O}_{3-\mathrm{y}}\right)$ Units. Journal of the American Ceramic Society. 2001; 84(10):2160-2166.

19. Schiavon MA, Redondo SUA, Pina SRO, Yoshida IVP. Invertigation on kinetcs of thermal decomposition in polysiloxane networks used as precursors of silicon oxycarbide glasses. Journal of Non-Crystalline Solids. 2002; 304(1-3):92-100.

20. Ozawa T. A new method of analyzing thermogravimetric data. Bulletin of the Chemical Society of Japan. 1965; 38(11):1881-1886.

21. Howe JY, Jones LE. Influence of boron on structure and oxidation behavior of graphite fiber, P120. Carbon. 2004; 42(3):461-467. 